\title{
A VIDA NO LIXO: UM ESTUDO DE CASO SOBRE OS CATADORES DE MATERIAIS RECICLÁVEIS NO MUNICÍPIO DE IPAMERI, GO
}

\author{
C. V. Gonçalves ${ }^{1}$, G. Malafaia ${ }^{2}$, A. L. S. Castro ${ }^{3}$ e B. G. A. Veiga ${ }^{4}$
}

cleber@gmail.com ${ }^{1}$, guilhermeifgoiano@gmail.com ${ }^{2}$, andreasl@yahoo.com.br ${ }^{3}$, bgaveiga@gmail.com ${ }^{4}$

Artigo submetido em fevereiro/2012 e aceito em abril/2013

\section{RESUMO}

O lixo ainda é um dos grandes problemas sócioambientais brasileiros. Nas unidades de destinação final de resíduos sem qualquer tipo de controle estão as condições de trabalho de uma parcela da população cada vez mais crescente e pouco reconhecida. Os catadores de materiais recicláveis são hoje objeto de inúmeras políticas públicas de inclusão social, mas que não tem o devido alcance nacional, sobretudo em pequenos municípios. Nesse contexto, essa pesquisa buscou identificar o perfil e condições de trabalho de catadores de material reciclável no município de Ipameri (GO), revelando que a situação local não é diferente de outras cidades brasileiras, mas o reconhecimento por parte do poder público pode vir a ser tardio em relação às grandes cidades onde o problema é mais aparente.

PALAVRAS-CHAVE: lixo, catadores, reciclagem.

\section{LIFE IN THE TRASH: A CASE STUDY ON RECYCLABLE MATERIALS IN IPAMERI, GO}

\section{ABSTRACT}

Garbage disposal is still a major social-environmental problem in Brazil. Waste Disposal Units are the working conditions of a ever increasing and not controlled, not even recognized, portion of the population. The recyclable material collectors are today the object of numerous public policies for social inclusion, but that does not have the proper reach, especially in small towns. This study aimed to identify the profile and working conditions of Waste Disposal Units gatherers in the city of Ipameri (GO), revealing that the situation is not different of that found in other Brazilian cities. The recognition of the problem by the public authority might be delayed when compared to large cities where the problem is more apparent.

KEY-WORDS: garbage collectors, recycling. 


\section{A VIDA NO LIXO: UM ESTUDO DE CASO SOBRE OS CATADORES DE MATERIAIS RECICLÁVEIS NO MUNICÍPIO DE IPAMERI, GO}

\section{INTRODUÇÃO}

No Brasil, segundo dados da Pesquisa Nacional de Saneamento Básico - PNSB (IBGE, 2002 e 2010), 59\% dos municípios brasileiros apresentava em 2000 o lixão como destino final dos resíduos sólidos, estatística que caiu para 50,8\% em 2010. Os lixões são definidos pelo IBGE como "locais utilizados para disposição do lixo, em bruto, sobre o terreno sem qualquer cuidado ou técnica especial, sem medidas de proteção ao meio ambiente ou à saúde pública".

Nesses ambientes insalubres e sem controles sanitário e ambiental encontram-se os catadores de materiais recicláveis, cujo número atual no país pode estar entre 300 mil e 1 milhão, segundo estimativa do Ministério do Desenvolvimento Social e de Combate à Fome, que coordena desde 2003 o Comitê Interministerial de Inclusão Social de Catadores de Materiais Recicláveis (MDS, 2013). No entanto, a PNSB (IBGE, 2002 e 2010) apontava a existência de apenas 24.340 catadores em lixões pelo país, informado por 1548 municípios que reconheciam a existência desses em 2000, mas 70.449 catadores informados por 1488 municípios em 2010, um crescimento de quase três vezes o número de catadores informados.

Os catadores de materiais recicláveis, antes reconhecidos como grupo excluído ou marginalizado, com uma origem que frequentemente se confunde com a da população em situação de rua, hoje contam com políticas públicas específicas de inclusão social do governo federal, tendo sido reconhecidos em 2002 pela Classificação Brasileira de Ocupações do Ministério do Trabalho e Emprego. Além disso, são considerados importantes prestadores de serviço ambiental à sociedade, na medida em que diminuem a quantidade de resíduos sólidos e seus impactos nas cidades brasileiras.

O Decreto no 5.940, de 2006, estimula os órgãos do serviço público federal a separar seus resíduos na fonte e destiná-lo à associações organizadas de catadores de materiais recicláveis. Essa iniciativa contribui deveras para a o fortalecimento desses atores sociais, mas quase sempre são desenvolvidas em grandes cidades, em que o problema social dos catadores é mais aparente. Boa parcela dos municípios brasileiros possui menos de 20 mil habitantes e essas políticas ainda não atingem nem reconhecem os catadores de materiais recicláveis que convivem com diferentes situações de disposição final inadequada dos resíduos sólidos.

Em 2010, foi sancionada a Política Nacional de Resíduos Sólidos (PNRS), considerada um avanço significativo na política ambiental brasileira (Brasil, 2010). Ao criar normas abrangentes para o gerenciamento de resíduos sólidos, a nova legislação responde a antigas demandas feitas não apenas por ecologistas, mas por toda a sociedade civil, diante do acúmulo exponencial de dejetos em áreas urbanas e rurais. A PNRS prevê que todos os municípios brasileiros elaborem um Plano Municipal de Gerenciamento de Resíduos Sólidos e ainda prevê que os catadores sejam alvo do plano e que sejam estabelecidas estratégias para reintegração desses indivíduos. Em adição, a PNRS torna obrigatória a elaboração dos planos inclusive pelos municípios com menos de 20 mil habitantes.

No estado de Goiás, apenas 65 municípios informaram à época da primeira PNSB (2002) a existência de catadores desenvolvendo atividades em lixões. Em 2008, a mesma pesquisa apontava que 151 prefeituras tinham conhecimento da atuação de catadores em área urbana. 
Do total de catadores em unidades de destino final, quase $17 \%$ tinham até 14 anos de idade, mas em 2008 esse montante caiu para aproximadamente 5\%. No município de Goiânia, boa parte não teve treinamento algum para entrar na atividade nem possuía qualquer tipo de registro ou benefício trabalhista, além de ter baixa escolarização e sofrer com a falta de oportunidade/emprego, fatores que acabam impulsionando os catadores para o trabalho no lixo (Ferreira et al, 2006).

De fato, a situação dos catadores apresenta-se de forma muito diferente, devido à diferença no modo como a sociedade e gestores públicos se relacionam com a questão. No passado, a existência de catadores representava a ineficiência dos serviços de limpeza urbana, e eles eram vistos como intrusos nos perímetros das unidades de destinação final. Entretanto, atualmente são "objeto" de políticas de inclusão social e vistos como prestadores de serviços ambientais à sociedade, o que convém melhorar as estatísticas sobre essa população.

Embora tenha havido muitos avanços no campo do saneamento básico no Brasil, problemas decorrentes da exposição da saúde humana aos agentes contaminantes e poluentes dos lixões continuam os mesmos, e são ainda mais graves quando se verifica a total falta de controle de administração pública em pequenos municípios. Cavalcante \& Franco (2007) destacam que a exposição da saúde humana e ambiental aos agentes danosos a partir dos lixões ocorre de duas formas: pelo modo direto, quando há um contato estreito do organismo humano com agentes patogênicos presentes no lixão, e pelo modo indireto, por meio da amplificação de algum fator de risco, que age de forma descontrolada sobre o entorno e por três vias principais, a saber: a ocupacional, a ambiental e a alimentar.

Segundo Gonçalves (2005), a via ocupacional particulariza-se pela contaminação dos catadores, que manipulam substâncias consideradas perigosas sem nenhuma proteção. Embora atinja uma parcela reduzida da população, esta via manifesta a forma mais agressiva de contaminação (Gonçalves, 2005). Por outro lado, a via ambiental caracteriza-se pela dispersão dos agentes contaminadores pelo ar, advindos da putrefação de restos alimentares e de animais mortos, infestação do chorume nos corpos d'água superficiais ou infiltração no lençol freático em solos permeáveis e pela produção de gás metano em virtude da decomposição dos resíduos ou proliferação de bactérias anaeróbias, o que, "além de contribuir para o efeito estufa (...), pode criar verdadeiras bombas" (Lima e Ribeiro, 2000, p. 53).

Diante desse contexto, em um cenário de vulnerabilidade e exclusão social, surge a necessidade de investigar sobre esse grupo populacional (os catadores de lixões) ainda muito negligenciado por autoridades públicas. Assim, no presente estudo foi analisado o perfil dos catadores de materiais recicláveis e suas condições de trabalho no lixão do município de Ipameri, Sudeste do Estado de Goiás. Acredita-se que este estudo possa contribuir para a compreensão dos desafios da inclusão social e melhoria da saúde humana e ambiental em municípios de pequeno porte.

\section{ESTRATÉGIA METODOLÓGICA}

\section{1. Área de Estudo}

O presente estudo foi desenvolvido no município de Ipameri, situado na região Sudeste do Estado de Goiás, especificamente na microrregião de Pires do Rio, região Centro-Oeste do Brasil. Em termos geográficos, Ipameri-GO limita-se ao norte com Luziânia-GO e Cristalina-GO; a 
nordeste com Paracatu-MG e Campo Alegre de Goiás-GO; ao sul com Goiandira-GO e Nova Aurora-GO; a sudeste com Corumbaíba-GO; a oeste com Caldas Novas-GO e Pires do Rio-GO e a noroeste com Urutaí-GO e Orizona-GO (Figura 1).

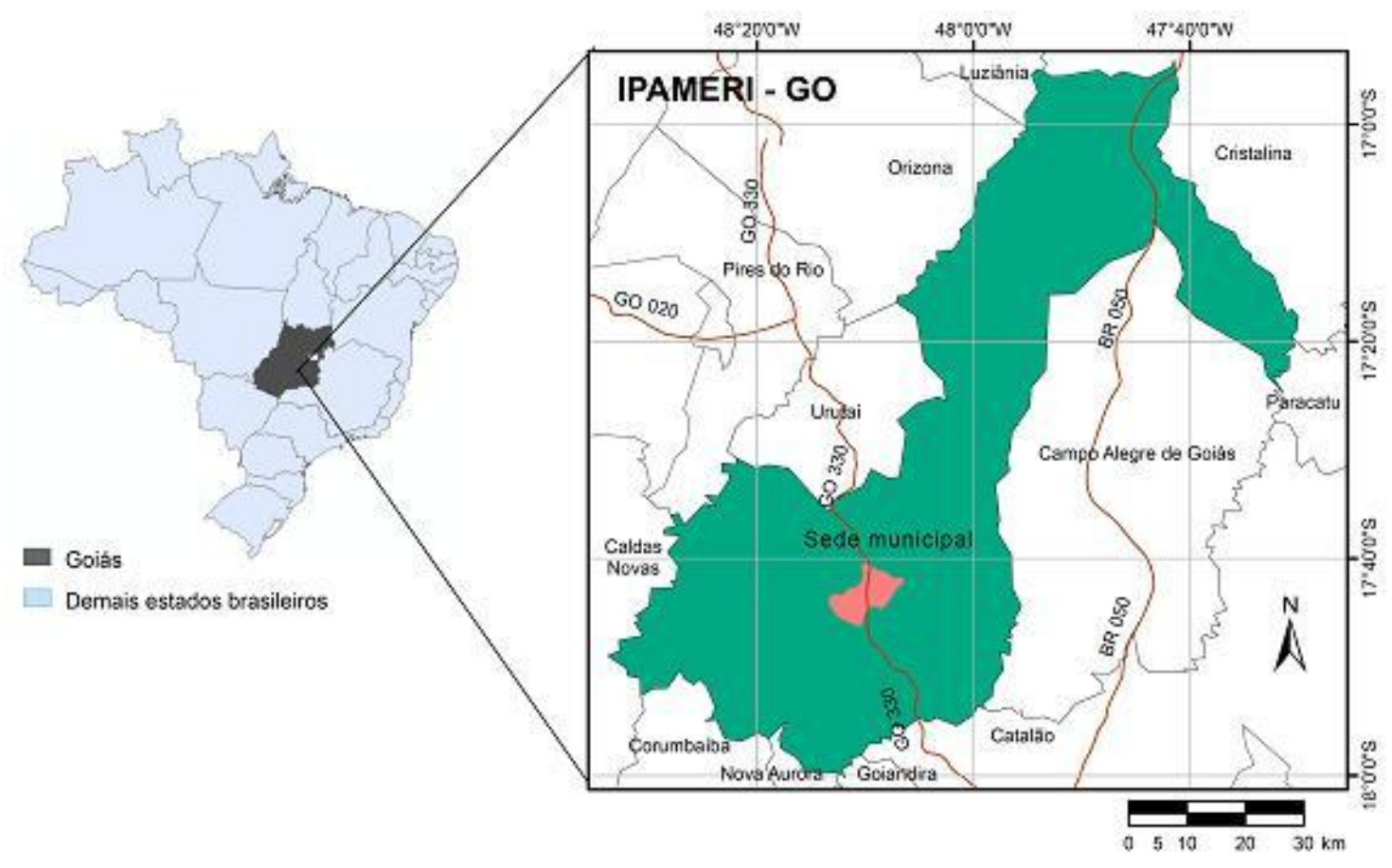

Figura 1. Mapa de localização do município de Ipameri-GO. Fonte: Firmino et al. (2010).

Com aproximadamente 24 mil habitantes, área de $4.369 \mathrm{~km}^{2}$ e $794 \mathrm{~m}$ de altitude (IBGE, 2010), o município apresenta como forma de destinação final dos seus resíduos sólidos em um lixão localizado na zona rural do mesmo.

A escolha desse município como objeto de estudo deu-se em função de irregularidades observadas na área destinada à disposição dos resíduos gerados no município e à problemática inerente relacionada às condições sociais e de qualidade de vida dos catadores de lixo que no lixão do município trabalham cotidianamente.

Segundo a Lei Municipal no 2363 de 2003, a destinação final de resíduos sólidos do município de Ipameri torna-se objeto de concessão mediante instrumento legal que prevê o pagamento pelo lixo tratado. Contudo, não estabelece os parâmetros técnicos necessários para a adequação, mesmo que mínima, do lixão. Observa-se na área que há um mínimo controle quanto à disposição de resíduos na mesma. De acordo com Vaz (2009), o lixão encontra-se a aproximadamente $5 \mathrm{~km}$ de distância da sede do município, ocupa uma área de 4 hectares, onde todo o lixo da cidade é despejado e acumulado a céu aberto, sem distinção ou triagem, (Figura 2), distante a mil metros de um córrego. 


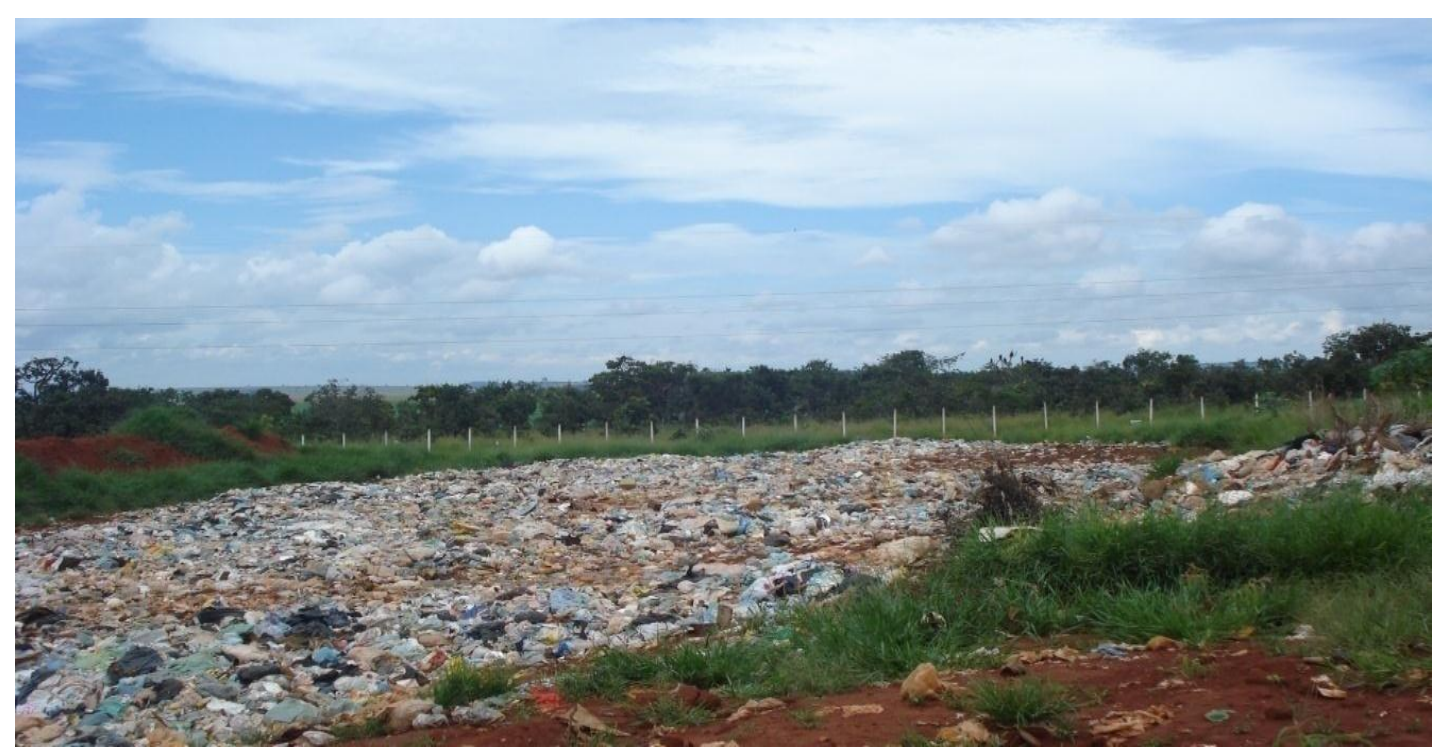

Figura 2. Vista geral do lixão do município de Ipameri, GO.

\subsection{Agentes estudados e coleta de dados}

Durante o mês de abril de 2008 foram realizadas 3 visitas ao local do lixão para identificação e avaliação da área, bem como a identificação das pessoas a serem entrevistadas. Nesse ambiente frequentavam na ocasião da realização da pesquisa de campo 12 catadores de material reciclável, organizados por uma cooperativa local.

$\mathrm{Na}$ ocasião, os dados primários foram coletados por meio de entrevista aberta com a Presidente da Cooperativa dos Catadores do Lixão de Ipameri e por meio da aplicação de um questionário estruturado junto aos catadores de materiais recicláveis. As entrevistas foram realizadas nos locais de trabalho dos participantes, mas em ambientes reservados - de modo que não houvesse interrupção - para deixá-los à vontade e imersos em suas realidades.

Tanto a entrevista quanto o questionário buscou explorar as formas de organização dos catadores no local, bem como os principais problemas que enfrentam na convivência com as condições de trabalho insalubres na área do lixão. Além disso, por meio dos questionários, buscou-se coletar informações sobre o perfil e as condições de trabalho dos catadores de materiais recicláveis no local, em num contexto de um pequeno município do interior do Estado de Goiás, diferentemente de contextos de municípios de médio e grande parte, como analisados em boa parte dos trabalhos publicados. Assim, foram levantadas questões sócio-econômicas básicas, bem como problemas relacionados ao trabalho na área do lixão. A observação direta das condições sanitárias do lixão também forneceu informações para a presente pesquisa.

\subsection{Questões éticas}

Durante a execução desse estudo as seguintes preocupações éticas foram levadas em consideração: i) apenas os sujeitos que aceitaram participar voluntariamente fizeram parte da amostra populacional desse estudo, ii) houve proteção do banco de dados durante o período da pesquisa, sob a guarda do coordenador da mesma; iii) há sigilo absoluto acerca de todas as informações coletadas, resguardada a privacidade dos participantes na apresentação dos resultados; v) há a garantia de que nenhum dado foi apresentado de forma individual, mas sim 
coletivamente, bem como o vi) o compromisso de retornar os resultados obtidos à Prefeitura Municipal de Ipameri e a quem interessar.

\section{RESULTADOS E DISCUSSÃO}

Segundo a presidente da Cooperativa dos Catadores do Lixão de Ipameri, que funciona no local desde novembro de 2007, nenhum dos 12 catadores de materiais recicláveis possui qualquer tipo de contrato, registro ou benefício trabalhista. A maior parte possui algum vínculo de parentesco, mas não existia presença de menores trabalhando na área na ocasião das visitas, nem mesmo informada pelos entrevistados.

Para ingressar na atividade, nenhum catador recebe treinamento ou qualquer forma de preparo para as condições insalubres da atividade. A prefeitura municipal auxilia apenas com o fornecimento de alguns medicamentos para prestação de primeiros socorros no local, em caso de acidentes leves e na vacinação preventiva dos cooperados.

Para a atividade, os catadores contam com uniformes, botas de borracha, máscaras descartáveis, os quais são fornecidos pela própria cooperativa. A renda média mensal individual obtida na atividade é de $\mathrm{R} \$ 670,00$, e o trabalho intensifica-se principalmente junto aos horários de despejo de lixo no local (5 despejos nas segundas-feiras e 3 despejos diários de terça a domingo). Apenas uma catadora conta com o auxílio bolsa-família, mas nenhum outro possui outra atividade ou renda extra.

O Compromisso Empresarial para Reciclagem (CEMPRE, 2008) estima que um catador nas regiões Sul e Sudeste obtém da atividade um salário mínimo e meio, e apenas um salário mínimo nas demais regiões, mas os ganhos obtidos pelos catadores vêm diminuindo com a desvalorização dos materiais (Ribeiro et al, 2009). No município de Goiânia, a média da renda dos catadores está abaixo de um salário mínimo (Ferreira et al, 2006).

O lixo recolhido pelo município de Ipameri não é a única fonte de resíduos para o local, havendo constantemente o uso por particulares que dispensam qualquer tipo de material, desde resíduos de construção civil até animais doentes. Embalagens de agrotóxicos são constantemente encontradas no lixão e o material hospitalar, após descarregado, é queimado no próprio local, a céu aberto.

As instalações da cooperativa são precárias, constando apenas de uma área coberta para guarda de equipamentos de proteção e armazenamento da água consumida diariamente, trazida por cada um dos catadores. A manutenção do local é representada apenas pela varrição, conforme a necessidade.

O manejo do lixo era representado apenas pela queima e mais raramente pelo entulhamento em valas do lixo não reciclável, seguido de sua cobertura após o enchimento total, com auxílio de um trator da prefeitura. Segundo os entrevistados, o lixo reciclável é vendido com separação grosseira a duas empresas particulares, uma do município de Catalão e outra de Caldas Novas, ambas próximas à Ipameri. Os preços praticados na época estão citados na tabela 1 , atingindo maiores valores apenas o alumínio e o cobre. Além da venda do lixo, metade dos catadores afirmou recolher roupas e equipamentos eletrônicos para seu próprio uso. 
Tabela 1 - Tipos de materiais recicláveis comercializados no lixão e preços de venda praticados pela Cooperativa de Catadores do Lixão de Ipameri.

\begin{tabular}{cc}
\hline Tipo de material reciclável & Preço de venda (R\$/kg) \\
\hline Cobre & 9,00 \\
\hline Metal & 4,00 \\
\hline Alumínio & 2,50 \\
\hline Plástico & 0,5 \\
\hline Papel & 0,15 \\
\hline Vidro & 0,005 \\
\hline
\end{tabular}

Dos 12 catadores de materiais recicláveis participantes da "Cooperativa dos Catadores do Lixão de Ipameri", apenas 7 estavam presentes nos dias da aplicação dos questionários, incluindo o administrador responsável pela sua gestão. Entre os respondentes, a maior parte era mulheres entre 25 e 33 anos $(71,4 \%)$, enquanto os dois catadores do sexo masculino $(28,6 \%)$ possuíam idade maior em relação às mulheres - 39 e 60 anos.

O tempo médio de atividade no lixão entre os catadores era de aproximadamente 10 meses, variando de 3 meses para o mais novato, mas com a idade mais avançada (60 anos), até 12 meses, na maior parte dos casos, representando o tempo em que o lixão vem funcionando no local. Em relação à escolaridade, apenas dois catadores concluíram o ensino médio, quatro concluíram o 50 ano do ensino fundamental e um não possuía nenhum nível de ensino formal concluído.

No caso de agravos à saúde causados pelas condições insalubres de trabalho, os sete catadores apontaram não ter sofrido qualquer problema de saúde física ou mental em decorrência do trabalho no lixão, devido à utilização de equipamentos mínimos de proteção e a vacinação preventiva. Nesse caso, vale salientar que se depreendeu dos debates que os catadores de lixo avaliam as condições de vida e saúde quantitativamente, ou seja, atêm-se à prioridade de ter que assegurar a sobrevivência e não com base numa medida qualitativa, que diz respeito ao prazer de viver, condição semelhante já sinalizada em estudos semelhantes (Rego et al., 2002; Dall'agnol \& Fernandes, 2007). Contudo, é importante ressaltar que os catadores que trabalham diretamente nos lixões convivem com riscos constantes, como gás metano, poeira, fogo, bem como outros tipos de resíduos químicos e tóxicos (Abreu, 2001; Souza \& Mendes, 2006). Porto et al. (2004), em pesquisa realizada sobre as condições de vida, trabalho e saúde com 218 catadores no aterro do Gramacho, no Rio de Janeiro, identificaram que 42,3\% dos trabalhadores se alimentam do que encontram no lixo. 0 estudo retrata ainda que $71,7 \%$ dos catadores já tiveram algum acidente (corte com vidro, topada, queimaduras, atropelamento, perfurações, quedas e contusões na cabeça), $72 \%$ reconhecem que existem riscos no local de trabalho, mas somente $47,5 \%$ identificam que esses riscos podem causar danos à saúde (Porto et al., 2004).

No presente estudo todos os catadores afirmaram ingressar na atividade no lixão devido à falta de oportunidades. Anteriormente à atividade no lixão os catadores desenvolviam atividades como empregadas domésticas, lavradores, costureiras, serventes de pedreiro e donas de casa. 0 desemprego, a necessidade de sustentar os filhos ou a enfermidade de parentes mais velhos foram apontadas como causas para o início da atividade como catador. Percebe-se nos discursos apresentados que a falta de oportunidades constitui um elemento fundamental para direcionamento ou permanência das pessoas nessa atividade. Por outro lado, conforme 
ressaltam Oliveira et al. (2008), a maneira como o catador vê sua atividade e posição social parece interferir em suas relações no mundo do trabalho. A representação social mais comum encontrada entre eles é a de que preferiam esse trabalho ao roubo, ao tráfico, à mendicância, o que reforça, sem querer, seu significado de miséria e exclusão e, também a auto-imagem destas pessoas como sem alternativas a não ser "viverem do lixo".

Segundo a Cooperativa, o processo de trabalho dos catadores é dividido em três fases: (i) na primeira, é realizada a coleta de materiais recicláveis ou de interesse pessoal dos catadores, tais como utensílios domésticos e alimentos, em meio a toda espécie de resíduos descarregados pelos caminhões; (ii) na segunda, é realizado o armazenamento do material recolhido num espaço individual delimitado pelo catador; e (iii) na terceira, é feita a comercialização destes materiais junto aos intermediários, utilizando-se com frequência o BIG BAG - uma saco com grande volume, fornecido pelas empresas compradoras de recicláveis.

Especificamente sobre a primeira etapa do trabalho dos catadores, evidencia-se uma situação que caracteriza uma condição desfavorável ao trabalhador, uma vez que os alimentos coletados no lixão são ingeridos pelos catadores e seus familiares. Apesar de os catadores não relatarem problemas de saúde, foi possível constatar que a alimentação de restos de comida oriundos dos resíduos que chegam ao lixão constituiu sério risco à saúde dessas pessoas, uma vez que estão expostos a vários tipos de contaminações e doenças.

Entre os catadores com menos tempo de experiência no lixão, observou-se uma menor preocupação com os riscos decorrentes da atividade, devido ao desejo de alcançar maiores rendimentos competindo com os colegas. Entre estes, a desinformação quanto aos agravos à saúde é ainda maior. Um dos catadores entrevistados afirma:

"Não vim pra cá de bobeira não, já vi muita gente ganhando dinheiro aqui na rampa, não tem que fazer corpo mole não, [..] eu também vim para ganhar dinheiro; estou garantindo o meu [...] aqui, quem entra na chuva, é pra se molhar, não fica olhando para o lado, para quem está adoentado."

Essa situação torna-se grave ao verificarmos que além de equipamentos precários de proteção, a disposição inadequada de resíduos no local por diferentes atores (prefeitura, cidadãos, empresas) acarreta a progressiva insalubridade do meio ambiente no local (Figura 3). A putrefação de restos alimentares e de animais mortos, a infiltração e escorrimento do chorume e a produção de gás metano em virtude da decomposição dos resíduos e proliferação de bactérias anaeróbias são apenas alguns dos problemas decorrentes do tratamento precário do lixo no local. 


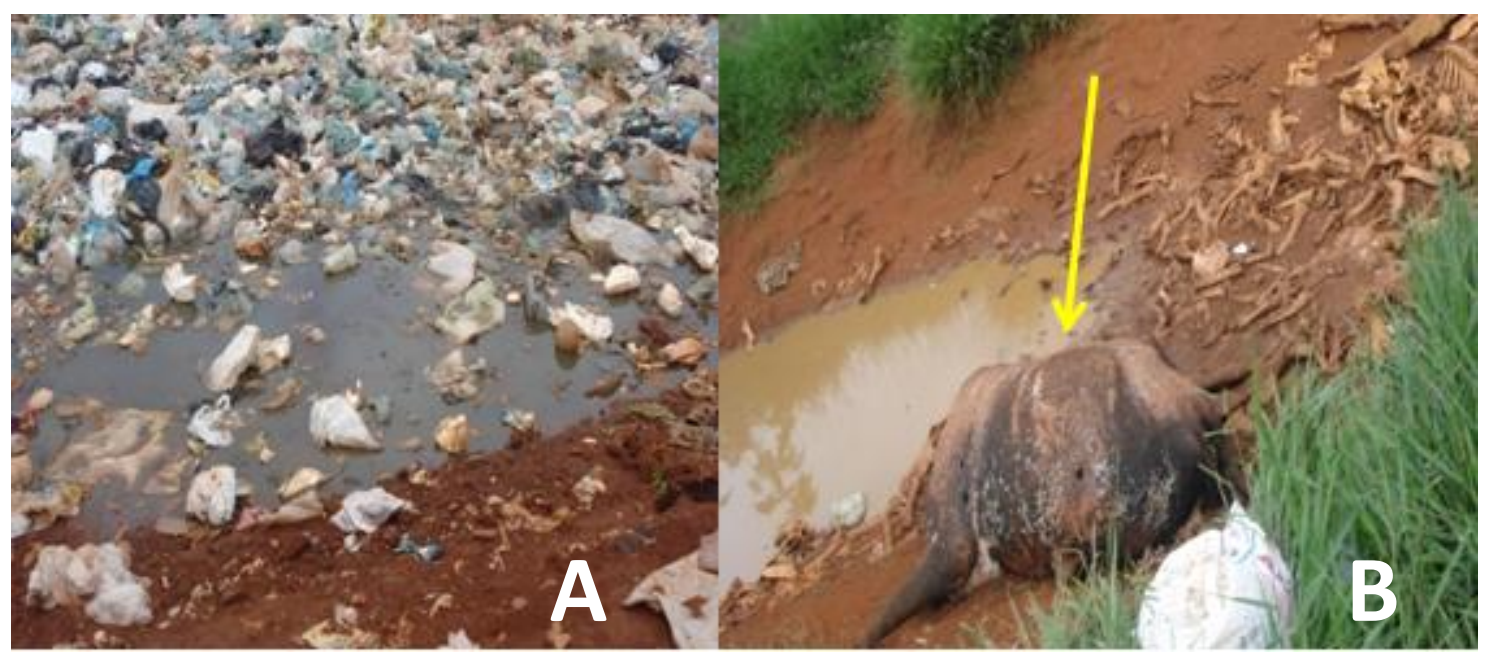

Figura 3. (A) Local de acúmulo de chorume e água de chuva e (B) Carcaça de animal doméstico deixado na área do lixão, Ipameri, GO.

Os espaços destinados ao descanso e alimentação dos catadores são pequenos barracos (Figura 4), sem as mínimas condições de higiene, e presença de moscas, baratas, ratos e um mau cheiro intenso. Todos os catadores entrevistados trazem suas refeições de casa.

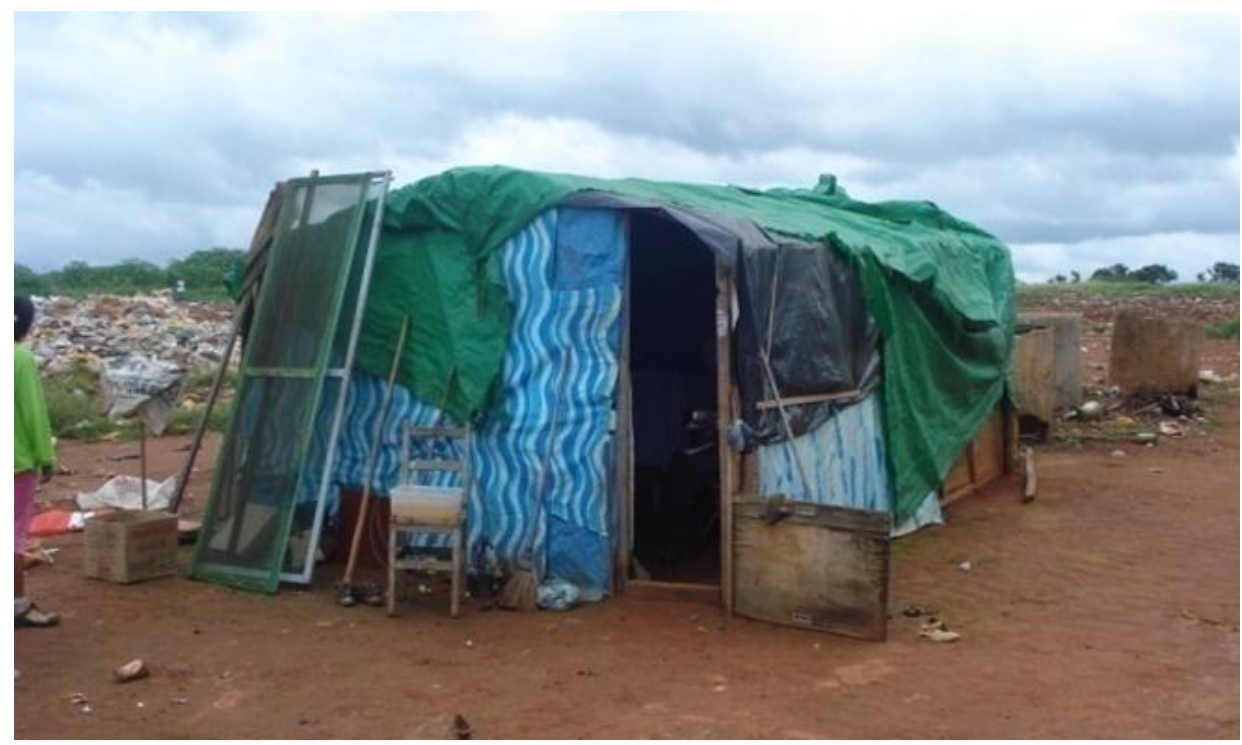

Figura 4. Barracos utilizados pelos catadores para descanso, armazenamento de materiais $\mathrm{e}$ refeições no lixão de Ipameri, GO.

Observações diretas realizadas nesse estudo corroboram as identificadas por Vaz (2009), as quais mostram a existência frequente de animais de criação, como gado e porcos, se alimentando dos restos do lixão, dividindo o espaço com os catadores de materiais recicláveis. Além disso, cães doentes são constantemente abandonados no local e passam a se alimentar também dos restos de lixo. Através dessas observações evidencia-se que os catadores cotidianamente trabalham sob condições subumanas.

Por outro lado, todos os catadores ressaltaram que apesar da dignidade encontrada em profissões anteriores, os rendimentos obtidos com a atividade de catação são bem maiores, além 
de possuírem maior liberdade quanto ao cumprimento de horários. Em função do baixo número de catadores, o local permite uma razoável exploração do lixão entre as poucas famílias participantes da cooperativa, que mantém entre si relações de parentesco.

A presidente da cooperativa demonstrou que procura manter um quadro mínimo de condições de saúde e segurança para os catadores, contando com o apoio da prefeitura. Vacinas antitetânica e anti-rábica são as que mais apresentam controle por escrito dos cooperados vacinados regularmente. Segundo a presidente da cooperativa, os catadores adotam medidas preventivas à saúde primordialmente quando um dos catadores sofre um acidente ou agravo mais sério.

Avaliando-se as informações obtidas sobre o perfil dos catadores, percebe-se que sua realidade não é nem um pouco distante da de outros catadores em diferentes cidades brasileiras. Silva \& Gonçalves (2009) afirmam que a organização dos catadores em cooperativas melhora a qualidade de vida dos cooperados, mas depende essencialmente de ajuda do poder público ou de outros agentes sociais. Contudo, foi observado que os catadores no lixão de Ipameri possuem uma relativa autonomia que se fortalece, sobretudo, pelos laços de parentesco existentes entre os cooperados, o que dificulta o ingresso de novas pessoas na atividade que não tenham relação familiar, mas que garante uma divisão razoável dos ganhos.

O apoio da prefeitura municipal é frágil e não existe nenhuma integração entre a disposição dos resíduos sólidos no local e a atividade dos catadores cooperados. No entanto, impressiona o fato de que nenhum dos cooperados tenha relatado qualquer ocorrência de agravo à saúde ou acidente de trabalho no período de um ano. Esse resultado pode estar relacionado com o desconhecimento ou mesmo a percepção dos catadores sobre o processo trabalho-doença, como apontaram Porto et al (2004) e Zacarias \& Bavaresco (2009), que se revela nos discursos dos catadores entrevistados que preferem adoecer do que verem os filhos passando necessidades.

Por fim, ressalta-se que a ausência de apoio adequado do poder público municipal e a inexistência de agentes sociais que lidem com os problemas enfrentados pelos trabalhadores informais em condições insalubres torna-se muito preocupante quando consideramos que os pequenos municípios interioranos estão ainda, na prática, muito distantes das políticas federais de inclusão social, como é o caso de Ipameri em Goiás. É necessário que as políticas públicas, como a PNRS extrapole seus preceitos para a prática cotidiana de milhares de pessoas que sofrem com condições insalubres de trabalho e de vida.

\section{CONSIDERAÇÕES FINAIS}

Atualmente no Brasil, com o debate sobre o desenvolvimento de instrumentos econômicos para a manutenção da qualidade ambiental, a reciclagem de materiais pode vir a tornar-se um importante serviço ambiental, realizado por catadores que contribuem para a sustentabilidade urbana, mas que acabam arcando com o ônus das condições insalubres de trabalho.

Nesse sentido, políticas de inclusão social devem buscar identificar, reconhecer e organizar esses indivíduos. No caso do município de Ipameri, verificou-se que o perfil desses catadores de materiais recicláveis que vivem do lixão municipal se assemelha ao de outros catadores em diferentes cidades brasileiras, exceto na renda obtida da atividade mantida dentro de uma organização quase que familiar. No entanto, os problemas enfrentados em termos de 
saúde e segurança do trabalho representam uma situação grave na medida em que o poder público local ou regional não mantém nenhum programa específico que atenda esses grupos, nesse e em outros municípios.

Nesse sentido, esperamos com esse trabalho contribuir para que uma maior atenção seja dispensada aos seres humanos que estão na condição de catadores de materiais recicláveis de Ipameri-GO, sem esquecer que tal atenção também deve emergir nos contextos vividos por tais trabalhadores em outras cidades, sobretudo, as de pequeno porte. Além desse alerta, há também a perspectiva de que, com a sistematização das informações aqui apresentadas, futuras ações sejam implementadas para fazer valer o reconhecimento dado aos catadores pelo próprio Ministério do Trabalho desde 2002, quando estabeleceu para a categoria os mesmos direitos e obrigações de um trabalhador autônomo, embora esse reconhecimento não represente o fim da luta dos catadores. Por fim, pode-se dizer que tomar a realidade de vida e de trabalho dos catadores investigados também representa uma reflexão muito positiva sobre nossas próprias posturas em relação a esses sujeitos.

\section{REFERÊNCIAS}

ABREU, M. F. Do lixo à cidadania: estratégias para a ação. Brasília: Caixa Econômica Federal, 2001.

BRASIL. Lei no 12.305, de 2 de agosto de 2010, que institui a Política Nacional de Resíduos Sólidos; altera a Lei no 9.605, de 12 de fevereiro de 1998; e dá outras providências. Disponível em:

http://bd.camara.gov.br/bd/bitstream/handle/bdcamara/4283/politica_residuos_solidos.pdf?se quence=1. Acesso em: 5 mar. 20113.

CAVALCANTE, S.; FRANCO, M.F.A. Profissão perigo: percepção de risco à saúde entre os catadores do Lixão do Jangurussu. Revista Mal Estar e Subjetividade, v. 7, n. 1, p. 211-231, 2007.

COMPROMISSO EMPRESARIAL PARA RECICLAGEM (CEMPRE). A evolução da coleta seletiva e reciclagem de resíduos sólidos urbanos no Brasil. Disponível em www.cempre.org.br. Acesso em: 20 maio 2010.

DALL'AGNOL, C.M.; FERNANDES, F.S. Saúde e autocuidado entre catadores de lixo: vivências no trabalho em uma cooperativa de lixo reciclável. Revista Latino-Americana de Enfermagem, v. 15, n. especial, p. 1-7, 2007.

FERREIRA J. A.; ANJOS, L. A. Aspectos de saúde coletiva e ocupacional associados à gestão dos resíduos sólidos municipais. Cadernos de Saúde Pública, v. 17, p. 689-696. 2001.

FERREIRA, O. M. Resíduos sólidos: Série material de apoio. Goiânia: Curso de Engenharia Ambiental da Universidade Católica de Goiás, 2008.

FERREIRA, S. L.; RABELO, F.C.; VASCONCELOS, S.M.S.; MARQUES, R.G.; MUNIZ, J.A.C. Importância ambiental do trabalho dos catadores de materiais recicláveis em Goiânia goiás brasil. In: Congreso Interamericano de Ingeniería Sanitaria y Ambiental, 30, Punta del Este, 26-30 nov. 2006.

FIRMINO, P. F.; MALAFAIA, G., RODRIGUES, A. S. L. Diagnóstico da integridade ambiental de trechos de rios localizados no município de Ipameri, Sudeste do Estado de Goiás, através de um 
protocolo de avaliação rápida. Brazilian Journal of Aquatic Science and Technology, 2011 (in press).

GONÇALVES. R. Catadores de materiais recicláveis: Trabalhadores fundamentais na cadeia de reciclagem do país. Revista Serviço Social e Sociedade, v. 82, n. 65, p. 87-109. 2005.

INSTITUTO BRASILEIRO DE GEOGRAFIA E ESTATÍ́STICA (IBGE). Banco de dados das Cidades. Disponível em: www.ibge.gov.br. Acesso em: 12 maio 2010.

INSTITUTO BRASILEIRO DE GEOGRAFIA E ESTATÍ́STICA (IBGE). Pesquisa Nacional de Saneamento Básico. IBGE: Rio de Janeiro, 2002. 397 p.

INSTITUTO BRASILEIRO DE GEOGRAFIA E ESTATístICA (IBGE). Pesquisa Nacional de Saneamento Básico. IBGE: Rio de Janeiro, 2010. 219 p.

LIMA, S. C., RIBEIRO, T. F. A coleta seletiva de lixo domiciliar: Estudos de casos. Caminhos de Geografia, 2, 50-69. 2000.

MINISTÉRIO DO DESENVOLVIMENTO SOCIAL E COMBATE À FOME (MDS). Parceria entre governo federal e catadores de papel visa gerar trabalho e renda. Disponível em: http://www.mds.gov.br/noticias/parceria-entre-governo-federal-e-catadores-de-papel-visagerar-trabalho-e-renda-1. Acesso em: 5 mar. 2013.

NUNESMAIA, M. F. A gestão de resíduos urbanos e suas limitações. Tecbahia-SSA, v. 17, n. 1, p. 120-122. 2002.

OLIVEIRA, M. M.; LUDWIG, M. P.; SILVA, P.F.G.; GRIFFITH, J.J. Lixo e trabalho sob o olhar de catadores de materiais recicláveis em ipatinga-mg. Oikos, v. 19, p. 33-52, 2008.

PORTO, M. F. S. ; JUNCÁ, D.C.M. ; GONÇALVES, R.S. ; FILHOTE, M.I.F. Lixo, trabalho e saúde: um estudo de caso com catadores em um aterro metropolitano no Rio de Janeiro, Brasil. Cadernos de Saúde Pública, Rio de Janeiro, v. 20, n. 6, p. 1503-1514, 2004.

REGO, R.C.F.; BARRETO, M.L.; KILLINGER, C.L. O que é lixo afinal? Como pensam as mulheres residentes na periferia de um grande centro urbano. Cadernos de Saúde Pública, v. 18, n. 6, p. 1583-1592, 2002.

RIBEIRO, J. C. F.; FRANKLIN, S.L.; FILIPECKI, A.T.P.; SILVA, E.R.; MATTOS, U.A.O. Catadores de materiais recicláveis: estudo de caso de uma cooperativa na cidade do Rio de Janeiro. In: Congresso Nacional de Excelência em Gestão. Disponível em www.excelenciaemgestao.org. Acesso em 25 de maio de 2010. Niterói, 2009.

SILVA, S. R. \& GONÇALVES, M. A. O trabalho no lixo: o caso da associação dos trabalhadores catadores de resíduos sólidos recicláveis do município de Nova Andradina- MS. In: XII Encontro de Geógrafos da América Latina. Disponível em http://egal2009.easyplanners.info. Acesso em 28 de maio de 2010. Montevideo, 2009.

SOUSA, C.M.; MENDES, A.M. Viver do lixo ou no lixo? A relação entre saúde e trabalho na ocupação de catadores de material reciclável cooperativos no Distrito Federal - Estudo exploratório. Revista Psicologia, v. 6, n. 2, p. 13-42, 2006.

VAZ, U. L. Impactos ambientais causados por sacolas plásticas e percepção ambiental dos comerciantes em Ipameri-GO. Monografia (Tecnologia em Gestão Ambiental). Urutaí, 2009. 42 p. 
ZACARIAS, I. R. \& BAVARESCO, C. S. Conhecendo a realidade dos catadores de materiais recicláveis da Vila Dique: visões sobre os processos de saúde e doença. Revista Textos \& Contextos, v. 8 n.2 p. 293-305, 2009. 